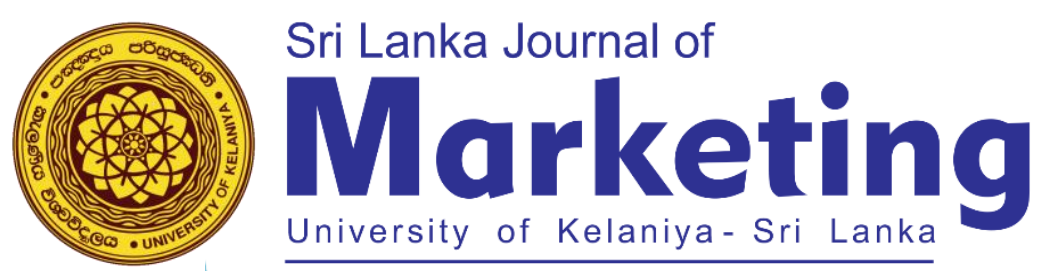

\title{
Drivers of the Purchasing Intention Provoked Via Facebook Advertising of Millennial Sri Lankans
}

\author{
Gayathree D. A. G. P. K. \\ Senior Lecturer, University of Kelaniya, Sri Lanka \\ poornima@kln.ac.lk \\ Bandara B. S. S. U. \\ Senior Lecturer, University of Kelaniya, Sri Lanka \\ saumya.uditha@kln.ac.lk \\ Navodani Thennakoon \\ Undergraduate, Department of Marketing Management, Kelaniya, Sri Lanka \\ navodanithennakoon6@gmail.com
}

\section{ABSTRACT}

Advertising plays a significant role in the current business world. In the digital platform, social media advertising is a new trend in developed and developing countries. In Sri Lanka, Facebook advertising covered a vaster audience compared to other platforms. There is a significant challenge to the business organizations in designing Facebook ads to successfully attract the target audience and motivate them to purchase the advertised products. Therefore, the primary purpose of the study is to analyze the effect of Facebook advertising to predict millennial consumers' purchase intention.

The conceptual framework comprises of performance expectancy, along with informativeness and perceived relevance. Further, gender plays a moderating role in this study. The data collected using a self-directed questionnaire distributed among 200 participants. The findings revealed that gender moderates the relationship between perceived relevance and performance expectancy and informativeness and performance expectancy. Informativeness of advertisements was a significant factor in purchasing intention.

Keywords: Facebook Advertising, Gender, Informativeness, Perceived Relevance, Performance Expectancy, Purchasing Intention, The Millennial Generation 


\section{INTRODUCTION}

\subsection{Background of the Study}

A crucial characteristic in the modern marketing arena is the widespread use of social media as a primary communication tool. The popularity of social media platforms emphasizes the shifts in media consumption from traditional media to digital media. According to Rapp (2013), around 88\% of the companies, including media, IT, automobile, FMCG, telecommunication, etc., have already used various social media platforms. Approximately $42 \%$ have fully incorporated different social media sites into their marketing strategies. Besides, large and small companies are also embracing the web to communicate with current and potential customers through the internet with a significantly less cost plan (Kiani, 1998). Therefore consumers are now interacting with the company, the media, and, most importantly, through social networking and other new media platforms (Winer, 2009).

Considering social media, it is increasingly connecting in all aspects of our lives. Consumers are increasing the usage of major social media platforms, such as Facebook, YouTube, Snapchat, and Twitter (Kim \& Kim, 2018). Thus, it has created a connection between marketers and other consumers, opening new possibilities and opportunities to increase consumer brand awareness (Media, 2009). Advertising specialists have started using social media marketing to attract consumers' attention and address their needs' customization. The objective is to motivate users to share the brand image and develop free advertising (Waters, Canfield, Foster, \& Hardy, 2011). However, Kotler (1999) mentioned that brands could speed up consumers' information dispatch, and brands can negatively and positively influence the perception of the associated products and services.

Statistics of the Sri Lankan's social media usage shows that there are 6.4 million monthly active Facebook users, 4.8 million monthly YouTube viewers, 1 million Instagram \& LinkedIn monthly active users, and 180,000 monthly active Twitter users as of August 2018. There are 6.3 million active smartphone users as of August 2018 (Facebook, 2018). Among the other social media platforms, Facebook is the world's largest Social Network Site (SNS), which reported 1.49 billion daily active users on average for September 2018 and 2.27 billion monthly active users in September 2018. Further, the global Facebook advertising revenue was around $\$ 13.5$ billion in $20183^{\text {rd }}$ quarter. (Facebook, 2018b)

The Facebook platform's largest audience represents 25-34 years old, which counts to 2.1 million users, comprised of 39\% of women and 38\% of men. According to Facebook statistics, 35\% of men and 39\% of women are doing management jobs. When considering the Facebook usage behavior in geographical wise western province represents the largest audience as a percentage of $50 \%$. The target audience is more likely to interact with the brand pages through the post reactions (40\%) and Facebook ad clicks (33\%) (Facebook, 2018). 
Therefore, the researchers believe that investigation on millennials' perception of brands created via the Facebook platform is significant to understand how communication types would be most stimulating and engaging for the youth market. Moreover, organizations worldwide have started thinking about using Facebook to attract customers and building a profitable marketing relationship with the target audience (Kamboj, Sarmah, \& Dwivedi, 2018).

A comparative study conducted by Logan, Bright, \& Gangadharbatla (2012) indicated that both entertainment and information positively impact the value of Facebook ads and TV ads. Researchers recently examined aspects sharping the user's perception, intention, and behavior towards social media marketing activities as 'Habit' or habitual behavior (Wu, Li, \& Chang, 2016). Nevertheless, customers are more likely to ignore social media ads if they feel a degree of privacy concern (Jung, 2017). As for social media ads, customers are more likely to be attached if they perceive the target ads as more useful and valuable (Rana, Dwivedi, Clement, \& Williams, 2017).

Most importantly, marketers always face challenges of planning and designing Facebook ads more effectively and attractively to create customer purchase intention towards the brands (Alalwan, 2018). When comparing with traditional mass media advertising or online advertising (used in Web 1.0 applications), firms can have more informative and interactive (two-way) communication with their customer audience (Lee, 2018). Several studies have found out social media ads would help firms accomplish their marketing objectives, such as creating customer awareness, building customer knowledge, increasing customer perception, and motivating customers towards the final purchase (Alalwan, 2018).

Thereby it is evident that many people have investigated the impact of the different factors affecting the purchasing intention on social media platforms. Many studies have focused on the applicability and efficiency of using social media for effective advertising (Alalwan, 2017). But those have not clearly shown a model to describe this relationship. Therefore, the researchers' effort here is to fill the literature gap of developing a comprehensive model to explain the factor's impact on social media advertising.

\subsection{Research Objectives}

To assess the impact of Facebook advertising on millennial consumers' purchase intention regarding the Sri Lankan context with the moderating effect of the demographic factor of gender.

- To determine the impact of perceived relevance on the performance expectancy and the purchasing intention.

- To determine the impact of informativeness on the performance expectancy and the purchasing intention. 
- To determine the mediating effect of performance expectancy on the relationship between perceived relevance and purchasing intention.

- To determine the mediating effect of performance expectancy on the relationship between informativeness and purchasing intention.

- To determine the moderating effect of gender on the relationship between performance expectancy and the purchasing intention.

- To determine the moderating effect of gender on the relationship between perceived relevance and performance expectancy.

- To determine the moderating effect of gender on the relationship between informativeness and the performance expectancy.

\section{CONCEPTUALIZATION}

\subsection{Purchasing Intention}

One of the research studies has defined purchasing intention as a probability that lies in the hands of the consumers who intend to purchase a particular product (Grewal, Monroe, \& Krishnan, 1998). Several research studies have determined that when consumers evaluate products or services positively in a favorable manner, then they have likability to buy the product, which is turned as purchase intention of a customer (Beatty \& Ferrell, 1998; Dittmar, Beattie, \& Friese, 1996; Hausman, 2000). According to Schiffman \& Kanuk (2009), Customers' decision to buy the product or purchase intention significantly depended on the product value and recommendations that other consumers have shared on different communication platforms.

\subsection{Social Media}

According to Saxena (2013), social media has become an essential platform for global marketing communications and is undertaking a larger share of advertising budgets, especially to reach the millennial generation. Further Saxena (2013), has shown the value of advertising on social media such as Facebook, YouTube, LinkedIn, Twitter, etc., great interest to organizations and marketers. Social media is defined as "online platforms that individuals use to share their ideas, experiences, etc. communicate with each other" (Hayta, 2013). Leung (2015) has pointed out that social media platforms' growth has changed how consumers interact with each other and organizations. Thus, this has changed the way that organizations attract and retain prospective consumers.

Nevertheless, marketers quickly have realized the influence of the social community in terms of interactivity that dramatically impacts consumers' purchase intention (Chandra, Goswami, \& Chouhan, 2012). According to Calderon, Lopez, and Pena, (2017), users who recognize their abilities generate a positive attitude towards using technological applications and social media and are more likely to feel 
safe to succeed in using these tools. Furthermore, social media development has a significant impact on the change in marketing communications and the consumer decision-making process. Ultimately it impacts the consumer purchase intention (Kozinets, Wojnicki, \& Wilner, 2010). As mentioned above, the Facebook platform is considered easy to use and widely spread social media platform worldwide (Ernst, Engesser, Büchel, \& Blassnig, 2017).

\subsection{Performance Expectancy}

Facebook is an online Social Networking Site that allows individuals to communicate and share their ideas, opinions \& interests related information via creating a page and personalized it (Duffett \& Wakeham, 2016). According to Dehghani \& Tumer (2015), Facebook advertising offers users or consumers the opportunity to interact actively or two way with the advertisers or brand pages, which allows them to "like," "share" and "comment" on the contents and to view which friends liked or shared same posts. Furthermore, Facebook creates comprehensive platforms for viral online recommendations (Smock, Ellison, Lampe, \& Wohn, 2011). These mentioned factors encourage advertisers to spend a reasonable portion of their budgets on Facebook advertising at less risk. Further, it allows identifying potential customers to target them with more appealing advertisements (Falls, 2009). Facebook advertisements can be available in both desktop and mobile versions (Marshall \& Krance, 2014).

According to the literature, the Performance Expectancy of online advertisements is one of the factors that impact consumer purchasing intention. It has been defined as "the degree to which a customer believes that using or engaging with the system will help them to gain more productive, useful and it enables to save their time and effort in social media platforms" (Alalwan, 2017), Facilitating conditions and effort expectancy or performance expectancy impact the customers' positive attitudes towards the Facebook platform and using this platform simple and easy way (Alalwan, 2018).

- H1: Performance expectancy of Facebook advertisements significantly influence on purchasing intention.

- H4: Performance expectancy mediates the relationship between perceived relevance and purchasing intention

- H5: Performance expectancy mediates the relationship between informativeness and purchasing intention

\subsection{Perceived Relevance}

The research study of Sin, Nor, \& Al-Agaga (2012), revealed a positive influence of perceived usefulness which means that extend customer believes social media platform helps them gain better performance. Furthermore, there is a positive influence of perceived usefulness on online purchase intention through social media platforms. Further, it is suggested that more respondents perceive that 
social media is useful in helping them to buy online. Finally, they will have more intention to purchase through social media platforms. Perceived relevance can also be called perceived usefulness. First, Davis defined that perceived relevance as 'the degree to which a person believes that using a specific system would improve and facilitate better job performance' (Davis F. D., Perceived usefulness, perceived ease of use and users acceptance of information technology, 1989). Jung, (2017) research was based on Davis's general definition of perceived relevance. She explained how perceived relevance could predict the customers' attention or interactivity towards Facebook's targeted ads or avoid targeted ads.

$H 2_{a}$ : Perceived relevance $(P R)$ of Facebook advertisements significantly influences performance expectancy.

$H 2_{b}$ : Perceived relevance (PR) of Facebook advertisements significantly influences purchasing intention.

\subsection{Informativeness}

Informativeness of online advertisement is another factor found in the literature that impacts purchasing intention (Rotzoll \& Haefner, 1990). They have defined Informativeness as the extent to which an organization can provide sufficient information to the customers and, based on that, whether customers would make purchasing decisions. A research study conducted by Logan et al (2012), mentioned that entertainment and Informativeness significantly impact social media ads and TV ads value. Further, Lee (2015) has indicated the impact of both Informativeness and advertising creativity on consumers' expression of how far advertisements are valuable for them. Saxena (2013) specifies that entertainment and Informativeness significantly impact the added value of social media ads. Informativeness was addressed by Pavlou, Liang, \& Xue (2007) and many other studies highlighted the importance of developing constructs on consumers' attitudes with a special reference to the role of Informativeness in digital commerce (Gao \& Koufaris, 2006; Taylor et al., 2011).

H3 $3_{a}$ : Informativeness (INF) of Facebook advertisements significantly influences performance expectancy.

$H 3_{b}$ : Informativeness (INF) of Facebook advertisements significantly influence purchasing intention. 


\subsection{Gender}

Gender is one of the most widely used bases for marketing segmentation (Darley \& Smith, 1995). Hunt \& Einstein (1981) specified that men and women have different preferences for responding to advertisements. Men are more likely to seek entertainment, leisure, and functional purposes, while women mainly use the internet for interpersonal communication on Facebook. Taylor et al. (2011) determined that there is an effect of gender differences on the perceived ads' feature on Facebook advertising (Wolin \& Korgaonkar, 2003).

Another research study determined that men are more likely to search for information, while women are more likely to exchange digital messages through the internet (Jackson, Ervin, Gardner, \& Schmitt, 2001). Apart from that, another researcher has investigated the same area, and his study showed that women tend to use social media to communicate with friends they already know. In contrast, men tend to discover new friends (Tufekci, 2008). According to Croft, Boddy, \& Pentucci (2007), there is evidence that the men attempt to find a short-cut to derive conclusions while women properly look into all the information included in the advertisement. Further, there were differences in how men and women communicate, nothing its potential usefulness in marketing. Social networking sites like Facebook may lead to more gender customized ads based on users' profiles, interests, and online behavior (Hoy \& Milne, 2010). When compared to women, men tend to perceive social advertising like Facebook advertising as useful information because men have a more information-oriented motivation than women in the digital platform (Taylor et al., 2011).

H6: The relationship between performance expectancy and purchasing intention is stronger for females

H7: The relationship between perceived relevance and performance expectancy is stronger for females

H8: The relationship between informativeness and performance expectancy is stronger for females

The relationships discussed above are shown graphically in figure 1 .

Figure 1: Conceptual Framework

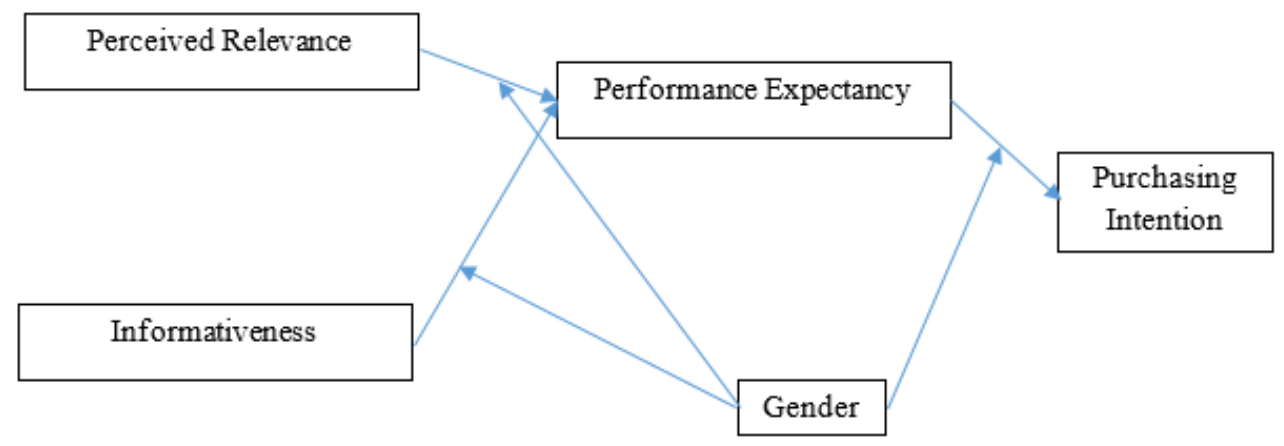




\section{METHODOLOGY}

The research design comprises a series of rational decision-making choices and organizes the research to gather data to analyze for the conclusion (Sekaran, 2003). The data collected at a single point in time from the sample. As the primary tool used for collecting data from the respondents, the questionnaire has developed with questions to obtain clear answers to achieve the objectives in this research study. The questionnaire has been designed with the support of previous literature and already validated scales. It was developed mainly under three sections to collect the data about Facebook advertising's influence on millennials' purchasing intention with the moderating effect of gender.

The study comprises of four constructs: two independent variables (Perceived Relevance, Informativeness), one mediator (Performance Expectancy), and one dependent variable (Purchasing Intention). Perceived Relevance is taken from Zeng, Huang \& Dou (2009), Informativeness is taken from Logan, Bright, \& Gangadharbatla (2012), Performance Expectancy is taken from Venkatesh, Thong, \& Xu (2012), and Purchasing Intention is taken from (Duffett \& Wakeham, 2016).

\section{DATA ANALYSIS}

\subsection{Demographic Profile}

Out of the 200 respondents, 110 were males, and 90 were females who contributed to the survey. As males dominated percentage gender distribution, $55 \%$ of the sample and $45 \%$ were female. The sample's age distribution is 18-25 years represented the largest age group of $69.5 \%$ percent of the whole sample group. The distribution of the age category of 26-34 years was $28.5 \%$, 35-44 years was $2 \%$ of the sample. As shown in the table, a large proportion of the sample group in terms of province represents the respondents living in Western Province, equivalent to $79 \%$. The second-largest ratio of $8 \%$ represents the Southern Province and then Central province 4\%, North Western Province 3.5\%, Uva and Sabaragamuwa provinces equality at $2.5 \%$ and North Central Province $0.5 \%$.

Table 01: Demographic Profile

\begin{tabular}{|l|l|c|c|}
\hline \multicolumn{1}{|c|}{ Measure } & \multicolumn{1}{|c|}{ Item } & Total & Percentage \\
\hline \multirow{3}{*}{ Gender } & Male & 110 & $55 \%$ \\
\cline { 2 - 4 } & Female & 90 & $45 \%$ \\
\hline \multirow{5}{*}{ Age } & $18-25$ & 139 & $69.5 \%$ \\
\cline { 2 - 4 } & $26-34$ & 57 & $28.5 \%$ \\
\cline { 2 - 4 } & $35-44$ & 4 & $2.0 \%$ \\
\hline \multirow{5}{*}{} & Western Province & 158 & $79.0 \%$ \\
\cline { 2 - 4 } & Central Province & 8 & $4.0 \%$ \\
\cline { 2 - 4 } & Southern Province & 16 & $8.0 \%$ \\
\cline { 2 - 4 } & Uva Province & 5 & $2.5 \%$ \\
\cline { 2 - 4 } & Sabaragamuwa Province & 5 & $2.5 \%$ \\
\hline
\end{tabular}




\begin{tabular}{|l|l|c|c|}
\hline & North Western Province & 7 & $3.5 \%$ \\
\cline { 2 - 3 } & North Central Province & 1 & $0.5 \%$ \\
\hline
\end{tabular}

Source: Survey Data

\subsection{Exploratory Factor Analysis (EFA)}

To test whether the observed variables are loaded to the variables, the correlation between those, reliability, and validity, Principle Component Analysis with Varimax rotation was used. In testing for the adequacy of the sample size, KMO and Bartlett's test values were reported. Kaiser-Meyer-Olkin Measure of sampling, which was 0.918, and Bartlett's Test of Sphericity reported 0.000 significance. These values show that the sample was sufficient to run the EFA. Further, the communalities of the observed variables were above 0.600 . Hence the sampling adequacy criteria have been met for the observed variables. Also, reliability was assessed using Cronbach's Alpha, and according to the values shown in the table, all are above the threshold of 0.70 , which is excellent.

Table 02: Reliability

\begin{tabular}{lll}
\hline Factor Label & Cronbach's Alpha & Specification \\
\hline Perceived Relevance & 0.808 & Reflective \\
Informativeness & 0.824 & Reflective \\
Performance Expectancy & 0.880 & Reflective \\
Purchasing Intention & 0.864 & Reflective \\
\hline
\end{tabular}

Source: Survey Data

The validity test was conducted to assess convergent validity and discriminant validity. The data meet the convergent validity since all the loadings exceed the threshold value of 0.350 (Hair, Black, Babin, \& Anderson, 2010). The correlations between the variables do not report values higher than 0.700 . Therefore, it can be concluded that the factors show the discriminant validity.

\subsection{Confirmatory Factor Analysis}

\subsubsection{Model Fit}

According to the below indices, the model fit of the model is sufficiently met. The observed variables were reported above 0.70 , except PE1, which is 0.660 , but the indicator was not removed since only three indicators available to the variable.

Table 03: Model Fit

\begin{tabular}{lll}
\hline Metric & Observed Value & Threshold \\
\hline cmin/df & 1.273 & Between $1-3$ \\
CFI & 0.991 & $>0.950$ \\
RMSEA & 0.037 & $<0.060$ \\
CLOSE & 0.775 & $>0.050$ \\
SRMR & 0.038 & $<0.090$ \\
\hline
\end{tabular}

Source: Survey Data 


\subsubsection{Validity and Reliability}

Reliability was assessed using Composite Reliability (CR), and Convergent Validity was assessed using Average Variance Extracted (AVE). Both meet the threshold values for all the variables concerned. That means CR exceeds the threshold of 0.700, and AVE exceeds the threshold of 0.500. Further, the variable's discriminant validity of the variables was met since AVE along the diagonal exceeds the correlations between the variables depicted in the below diagram.

Table 04: Validity and Reliability

\begin{tabular}{lcccccc}
\hline & CR & AVE & PE & PR & INF & PI \\
\hline PE & 0.811 & 0.592 & $\mathbf{0 . 7 6 9}$ & & & \\
PR & 0.873 & 0.697 & 0.742 & $\mathbf{0 . 8 3 5}$ & & \\
INF & 0.831 & 0.622 & 0.577 & 0.756 & $\mathbf{0 . 7 8 8}$ & \\
PI & 0.883 & 0.716 & 0.651 & 0.772 & 0.728 & $\mathbf{0 . 8 4 6}$ \\
\hline Source Survey Data & & & &
\end{tabular}

\subsubsection{Response Bias (Common Method Bias)}

The study used one single instrument (Survey) to collect data for both the IV's and DV's. Therefore, the Measurement model was run with CLF for the unconstrained and constrained variance. The test shows that there is a significant difference between the two models. The explanation means that the common method bias exists. Hence CLF will be kept when imputing factor scores.

\subsubsection{Invariance Tests}

The researchers expect to carry out a multi-group analysis in the study. Therefore, invariance analysis was conducted. In testing for configural invariance a good model fit $(\mathrm{cmin} / \mathrm{df}=1.240, \mathrm{CFI}=0.984)$ was reported when the test was conducted freely, i.e. without constraints. This reflects that the test for configural invariance was met for the data. Metric invariance is good since the chi-square difference test between fully constrained and the unconstrained models reported as not significant. Scalar invariance was met with model comparison p-value 0.072 .

\subsubsection{Final measurement model fit:}

Table 05: Final Measurement Model Fit

\begin{tabular}{lll}
\hline Metric & Observed Value & Threshold \\
\hline cmin/df & 0.779 & Between 1-3 \\
CFI & 1.000 & $>0.950$ \\
RMSEA & 0.000 & $<0.060$ \\
CLOSE & 0.994 & $>0.050$ \\
\hline
\end{tabular}




\begin{tabular}{lll}
\hline SRMR & 0.019 & $<0.090$ \\
\hline Source: Survey Data
\end{tabular}

Source: Survey Data

\subsection{Structural Model and Hypothesis Testing}

\subsubsection{Multivariate Assumptions}

Cook distance was performed to determine the influential outliers, but no value exceeded cooks' distance greater than one, where in most cases, the values were less than 0.15. It was tested the Variation Inflation Factor of independent variables on the dependent variables. All the values reported less than two, which is far less than the threshold values of 10 .

\subsubsection{Hypothesis}

The below analysis shows the significance of the relationship between variables. First direct effects are analyzed, which includes the mediator. Next, the mediation effect and moderation effects will be analyzed. The following list shows the direct, mediation, and moderation effects that are analyzed in the study.

- H1: Performance expectancy significantly influence on purchasing intention.

- H2a: Perceived relevance significantly influences performance expectancy.

- H2: Perceived relevance significantly influences purchasing intention.

- H3 $3_{a}$ : Informativeness significantly influences performance expectancy.

- H3 $3_{b}$ : Informativeness significantly influence purchasing intention.

- H4: Performance expectancy mediates the relationship between perceived relevance and purchasing intention

- H5: Performance expectancy mediates the relationship between informativeness and purchasing intention

- H6: The relationship between performance expectancy and purchasing intention is stronger for females

- H7: The relationship between perceived relevance and performance expectancy is stronger for females

- H8: The relationship between informativeness and performance expectancy is stronger for females 


\subsubsection{Hypothesis Testing}

Direct effects were analyzed using the beta coefficients and the respective significant values of the paths. The mediating effect are analyzed using the bootstrapping method with 2000 bias-corrected resamples. The multi-group effect was analyzed using the significance of the difference between the two groups. This is done with the chi-square test. The summary of the data is shown in the table below.

Table 05: Hypothesis Summaries

\begin{tabular}{|c|c|c|c|}
\hline \multicolumn{4}{|l|}{ Hypothesis Summary Table } \\
\hline Direct Effects & Evidence & \\
\hline $\begin{array}{l}\text { Performance expectancy significantly influences } \\
\text { purchasing intention }\end{array}$ & Beta: $0.163 *$ & \multicolumn{2}{|l|}{ Yes } \\
\hline $\begin{array}{l}\text { Informativeness significantly influences purchasing } \\
\text { intention }\end{array}$ & Beta: $0.714 * * *$ & \multicolumn{2}{|l|}{ Yes } \\
\hline $\begin{array}{l}\text { Perceived relevance significantly influences } \\
\text { purchasing intention }\end{array}$ & Beta: $0.095(\mathrm{~ns})$ & \multicolumn{2}{|l|}{ No } \\
\hline $\begin{array}{l}\text { Perceived relevance significantly influences } \\
\text { performance expectancy }\end{array}$ & Beta: $0.331 * *$ & \multicolumn{2}{|l|}{ Yes } \\
\hline $\begin{array}{l}\text { Informativeness significantly influences performance } \\
\text { expectancy }\end{array}$ & Beta: $0.037(\mathrm{~ns})$ & \multicolumn{2}{|l|}{ No } \\
\hline Mediation & Evidence & \multicolumn{2}{|l|}{ Supported? } \\
\hline $\begin{array}{l}\text { Performance expectancy mediates the relationship } \\
\text { between perceived relevance and purchasing } \\
\text { intention. }\end{array}$ & $\begin{array}{l}\text { Direct w/o Med: } 0.09(\mathrm{~ns}) \\
\text { Direct w/ Med: }-0.005(\mathrm{~ns}) \\
\text { Indirect: } 0.099(\mathrm{~ns})\end{array}$ & \multicolumn{2}{|c|}{ No Mediation } \\
\hline $\begin{array}{l}\text { Performance expectancy mediates the relationship } \\
\text { between informativeness and purchasing intention. }\end{array}$ & $\begin{array}{l}\text { Direct w/o Med: } 0.55^{* * *} \\
\text { Direct w/ Med: } 0.756^{* * *} \\
\text { Indirect: }-0.208 * *\end{array}$ & $\begin{array}{l}\text { Yes: } \\
\text { Mediation }\end{array}$ & Partial \\
\hline \multicolumn{4}{|l|}{ Multi-group moderation } \\
\hline $\begin{array}{l}\text { The relationship between performance expectancy } \\
\text { and purchasing intention is stronger for females }\end{array}$ & $\begin{array}{l}\text { Males: }-0.750 * * * \\
\text { Females: }-0.740 * * * \\
\Delta \text { Zscore: } 0.022(\mathrm{~ns})\end{array}$ & No & \\
\hline $\begin{array}{l}\text { The relationship between perceived relevance and } \\
\text { performance expectancy is stronger for females }\end{array}$ & $\begin{array}{l}\text { Males: }-0.140^{* *} \\
\text { Females: }-0.150^{* *} \\
\Delta \text { Zscore: } 3.288^{*}\end{array}$ & $\begin{array}{l}\text { Yes: } \\
\text { Stronger } \\
\text { Females }\end{array}$ & for \\
\hline $\begin{array}{l}\text { The relationship between informativeness and } \\
\text { performance expectancy is stronger for females }\end{array}$ & $\begin{array}{l}\text { Males: } 0.300^{* *} \\
\text { Females: } 0.310^{* *} \\
\Delta \text { Zscore: } 3.906^{* *}\end{array}$ & $\begin{array}{l}\text { Yes: } \\
\text { Stronger } \\
\text { Females }\end{array}$ & for \\
\hline
\end{tabular}

Source: Survey Data 


\section{CONCLUSIONS AND RECOMMENDATIONS}

\subsection{Conclusions}

Social media has become a powerful tool that has been used in marketing strategy. Therefore, researchers continuously seek the significance of advertising in social media platforms on the customer's purchasing intention. Alawan (2018) highlights that the factors identified towards purchasing intention concerning Social Media advertising shall be tested to determine the demographic factors' moderating effect. Hence, the prime researcher's purpose is to assess the strength of the relationships with the moderating effect of gender. The results clearly show that gender moderates the relationship between perceived relevance -> performance expectancy and Informativeness -> performance expectancy. Especially these relationships are more substantial for females than males.

\subsection{Recommendations}

The findings revealed that performance expectancy is a partial mediator between the informativeness and purchasing intention. Further, the relationship between perceived relevance and performance expectancy is stronger for females, and the relationship between informativeness and performance expectancy is stronger for females. Therefore, when designing the advertising content in the social media platforms, attention should be given regarding the informativeness and the target group to which the advertisements are designed. For example, products such as ladies' garments, cosmetics, and personal care items are widely advertised and sold via social media platforms. These products are purchased by the females where the advertising content will act as a significant determinant in buying the product.

\subsection{Further Research Areas}

The study focused on millennials and the data collected via the survey by providing self-directed questionnaires. Hence, future research could be conducted as an experiment that will allow testing the variables in a more controlled environment. Moreover, researchers can study the social media-based purchasing patterns by giving equal weight to various social media platforms available apart from Facebook. 


\section{REFERENCES}

Alalwan, A. A., Rana, N. P., Dwivedi, Y. K., \& Algharabat, R. (2017). Social media in marketing: A review and analysis of the existing literature. Telematics and Informatics, 34(7), 1177-1190.

Alalwan, A. A. (2018). Investigating the impact of social media advertising features on customer purchase intention. International Journal of Information Management, 42 (2018) 65-77.

Beatty, S. E., \& Ferrell, M. E. (1998). Impulse buying: Modeling its precursors. Journal of Retailing, 169-191.

Calderon, C. A., Lopez, M., \& Pena, J. (2017). The Conditional Indirect Effect of Performance Expectancy in the Use of Facebook, Google+, Instagram and Twitter by youngsters. Revista Latina de Comunicación Social, 590-607.

Chandra, B., Goswami, S., \& Chouhan, V. (2012). Investigating attitude towards online advertising on social media - an empirical study. Management Insight, 1-14.

Darley, W. K., \& Smith, R. E. (1995). Gender differences in information processing strategies: An empirical test of the selectivity model in advertising response. Journal of Advertising, 41-56.

Davis, F. D. (1989). Perceived usefulness, perceived ease of use, and user's acceptance of information technology. MIS Quarterly, 319-340.

Dehghani, M., \& Tumer, M. (2015). A research on effectiveness of Facebook advertising on enhancing. Journal of Computers in Human Behavior, 597-600.

Dittmar, H., Beattie, J., \& Friese, S. (1996). Objects, decision considerations and self-image in men's and women's impulse purchases. Acta Psychologica, 187-206.

Duffett, R. G., \& Wakeham, M. (2016). Social Media Marketing Communications Effect on Attitudes among Millennials in South Africa. The African Journal of Information System, 20-29.

Ernst, N., Engesser, S., Büchel, F., \& Blassnig, S. (2017). Extreme parties and populism: an analysis of Facebook and Twitter across six countries. Journal of Information, Communication \& Society, 1-18.

Facebook. (2018). Facebook Audience Insight - Sri Lanka. Facebook.

Facebook. (2018b). facebook Q3 2018 Results. Menlo Park, California, United States of America.

Falls, J. (2009). Public relations pros must be social media-ready. Journal of Social Media Explorer.

Gao, Y., \& Koufaris, M. (2006). Perceptual antecedents of user attitudes in electronic commerce. Acm Signals Database, 42-50.

Grewal, D., Monroe, K. B., \& Krishnan, R. (1998). The effect of price comparison advertising on buyers' perception of acquisition of value, transaction value, and behavioral intention. Journal of Marketing, 46-59.

Hair, J. F., Black,, W. C., Babin, , B. J., \& Anderson, , R. E. (2010). Multivariate data analysis (7th ed. ed.). Upper Saddle River, NJ: Prentice-Hall.

Hausman, A. (2000). A multi-method investigation of consumer motivations in impulse buying behavior. Journal of consumer marketing, 403-426.

Hayta, A. B. (2013). A study on the effects of social media on young consumers' buying behaviors. European Journal of Research on Education, 65-74. 
Hoy, M., \& Milne, G. (2010). Gender differences in privacy-related measures for young adult Facebook users. Journal of Interactive Advertising, 2.

Hunt, R. R., \& Einstein, G. O. (1981). Relational and item-specific information in memory. Journal of Verbal Learning and Verbal Behavior, 497-514.

Jackson, L. A., Ervin, K. S., Gardner, P. D., \& Schmitt, N. (2001). Gender and the Internet: Women Communicating. 363-379.

Jung, A. (2017). The influence of perceived ad relevance on social media advertising. Computers in Human Behavior, 303-309.

Kamboj, Sarmah, \& Dwivedi, \&. (2018). Examining branding co-creation in brand communities on Social media. International Journal of Information Management, 248-265.

Kiani, G. R. (1998). Marketing opportunities in the digital world. 158-194.

Kim, N., Kim, W (2018). Do your social media lead you to make social deal purchases? Consumer-generated social referrals for sales via social commerce. International Journal of Information Management, 38-48.

Kotler, P. (1999). Marketing Management: Analysis, planning, implementation \& control (10th edition).

Kozinets, R. V., Wojnicki, A. C., \& Wilner, S. J. (2010). Networked narratives: Understanding word-of-mouth marketing in online communities. Journal of Marketing, 71-89.

Lee, M. K. (2018). The role of consumer engagement. International Journal of Information Management, 113.

Lee, T. (2005). The impact of perceptions of interactivity on customers trust and transaction intention in mobile commerce. Journal of Electronic Commerce Research, 165-180.

Leung, X. B. (2015). The marketing effectiveness of social media in the hotel industry: a comparison of Facebook and Twitter. Journal of Hospitality \& Tourism Research, 147-169.

Logan, K., Bright, L.F., \& Gangadharbatla, H. (2012). Facebook versus television. Journal of Research Research in Interactive Marketing, 164-179.

Marshall, p., \& Krance, K. (2014). Ultimate Guide to Facebook Advertising: How to Access 1 Billion Potential Customers in 10 Minutes.

Media, C. (2009). Total number of unique visitors to selected social networking sites.

Pavlou, P., Liang, H., \& Xue, Y. (2007). Understanding and mitigating uncertainty in online exchange relationship . A principal agenda perspective, 105-1301.

Rana, N.P., Dwivedi, Y.K., Lal, B. et al. Citizens' adoption of an electronic government system: towards a unified view. Information Systems Frontier, 19, 549-568 (2017). https://doi.org/10.1007/s10796-015-9613-y

Rapp, A. B. (2013). Understanding social media effects across seller, retailer, and consumer interactions. Journal of the Academy of Marketing Science, 547-566.

Rotzoll, K. B., \& Haefner, J. E. (1990). Advertising in contemporary society (2nd ed.). South-Western Publishing.

Saxena, A. a. (2013). A structural equation modelling approach". Journal of Advertising on social network sites, 17-25. 
Schiffman, L., \& Kanuk, L. (2009). Consumer Behavior (10th ed.). Prentice-Hall.

Sekaran, U., \& Bougie, R. (2003). Research methods for business: A skill-building approach. John Wiley \& Sons.

Sin, S., Nor, K. M., \& Al-Agaga, A. M. (2012). Factors Affecting Malaysian young consumers' online purchase intention in social media websites. Journal of Social and Behavioral Science, 326-333.

Smock, A. D., Ellison, N. B., Lampe, C., \& Wohn, D. Y. (2011). Facebook as toolkit; A uses and gratification approach to unbundling feature use. Journal of Computers in Human Behavior, 2322-2329.

Sposito, V. A., Hand, M. L., \& Skarpness, B. (1983). On the efficiency of using the sample kurtosis in selecting optimal lpestimators. Communications in Statistics-simulation and Computation, 12(3), 265-272.

Taylor, D. G., Lewin, J. R., \& Strutton, D. (2011). Friends, Fans, and Followers: Do ads work on social networks: How gender and age shape receptivity. Journal of Advertising Research, 258-275.

Tufekci, Z. (2008). Grooming, Gossip, Facebook and Myspace. Journal of Information, Communication \& Society, 544-564.

Venkatesh, V., Thong, J. Y., \& Xu, X. (2012). Consumer acceptance and use of information technology: Extending the unified theory of acceptance and use of technology. MIS Quarterly, 36(1), 157-178.

Waters, R.D., Canfield, R.R., Foster, J.M., Hardy, E.E., (2011). Applying the dialogic theory to social networking sites. Journal of Social Marketing, 211-227.

Winer, R. S. (2009). New Communications Approaches in Marketing: Issues and Research Directions. Journal of International Marketing, 109-117.

Wolin, L. D., \& Korgaonkar, P. (2003). Web advertising: gender differences in beliefs, attitudes, and behavior. Internet Research, 375-385.

Wu, Y., Li, I., \& Chang, W. (2016). Nurturing user creative performance in social media networks. Internet Research, 869-900.

Zeng, F., Huang, L., \& Dou, W (2009) Social Factors in User Perceptions and Responses to Advertising in Online Social Networking Communities, Journal of Interactive Advertising, 10:1, 1-13 